\title{
MULTI-DATE SENTINEL1 SAR IMAGE TEXTURES DISCRIMINATE PERENNIAL AGROFORESTS IN A TROPICAL FOREST-SAVANNAH TRANSITION LANDSCAPE
}

\author{
F. N. Numbisi ${ }^{1,2^{*}}$, F. Van Coillie ${ }^{1}$, R. De Wulf ${ }^{1}$ \\ ${ }^{1}$ Ghent University, Laboratory of Forest Management and Spatial Information Techniques, Coupure Links 653, 9000 Gent, Belgium \\ - frednumbisi@gmail.com, (Frederick.NkeumoeNumbisi, Frieke.Vancoillie, Robert.DeWulf) @UGent.be \\ ${ }^{2}$ World Agroforestry Centre (ICRAF), West and Central Africa Regional Programme, PO Box 16317, Yaoundé, Cameroon
}

\section{WG I/3, 8}

KEY WORDS: Sentinel1 SAR, GLCM textures, Random Forest Algorithm, Perennial Agroforestry Mapping, REDD+ Strategy, Congo Basin Rainforest

\begin{abstract}
:
Synthetic Aperture Radar (SAR) provides consistent information on target land features; especially in tropical conditions that restrain penetration of optical imaging sensors. Because radar response signal is influenced by geometric and di-electrical properties of surface features', the different land cover may appear similar in radar images. For discriminating perennial cocoa agroforestry land cover, we compare a multi-spectral optical image from RapidEye, acquired in the dry season, and multi-seasonal C-band SAR of Sentinel 1: A final set of 10 (out of 50) images that represent six dry and four wet seasons from 2015 to 2017. We ran eight RF models for different input band combinations; multi-spectral reflectance, vegetation indices, co-(VV) and cross-(VH) polarised SAR intensity and Grey Level Co-occurrence Matrix (GLCM) texture measures. Following a pixel-based image analysis, we evaluated accuracy metrics and uncertainty Shannon entropy. The model comprising co- and cross-polarised texture bands had the highest accuracy of $88.07 \%$ (95\% CI: 85.52 - 90.31) and kappa of 85.37; and the low class uncertainty for perennial agroforests and transition forests. The optical image had low classification uncertainty for the entire image; but, it performed better in discriminating non-vegetated areas. The measured uncertainty provides reliable validation for comparing class discrimination from different image resolution. The GLCM texture measures that are crucial in delineating vegetation cover differed for the season and polarization of SAR image. Given the high accuracies of mapping, our approach has value for landscape monitoring; and, an improved valuation of agroforestry contribution to REDD+ strategies in the Congo basin sub-region.
\end{abstract}

\section{INTRODUCTION}

\subsection{Background}

Earth observation systems provide opportunities for resourceefficient and reliable monitoring of land cover changes, especially in inaccessible terrains and vast landscapes. Yet, in equatorial Africa and similar rainforest regions elsewhere, the use of optical satellite imagery is often limited to cloud-free images collected in a dry season. Since plant phenology is a function of season, such mono-temporal (dry seasonal) land cover maps often produce poor quality vegetation maps.

Amongst perennial agroforestry land use types, cocoa agroforestry systems (CAFs) have a marked importance in tropical sub-Saharan Africa, and in Cameroon in particular. Such shaded (multi-canopy strata) cocoa production is known to sequester carbon at rates comparable to transition forests (Norgrove and Hauser, 2013). As cocoa agroforests are fairly similar to transition forest in canopy structure (Sonwa et al., 2016), they may be simply mistaken for each other in land cover mapping based on reflectance values and vegetation indices. Thus, a sustainable management of such perennial cocoa agroforests, amongst others, in the context of REDD+ (Reducing Emissions from Deforestation and Forest Degradation and the role of conservation, sustainable management of forests and enhancement of forest carbon stocks in developing nations) strategies in the Congo Basin, may not be achieved without reliable procedures to estimate the land use expanse at local, country, and regional scales.

Synthetic Aperture Radar (SAR) images provide cloud and season independent information about land surface features. SAR thus is able to provide high temporal resolution images in tropical forest regions with frequent cloud cover. For example, Sentinel1 SAR, as the first operational satellite constellation of European Space Agency's (ESA) Copernicus programme, provides continuous C- Band SAR images at a 6 to 12-day time lapse (Copernicus, 2017).

SAR data have a wide range of applications from mapping forest and cropland cover to estimation of vegetation parameters such as height and biomass (Solberg et al., 2014): Assuming that similar analysis procedures are used, the mapping of vegetation cover from C-Band SAR images is less accurate than the L-Band SAR (Schmullius et al., 2015). The SAR backscatter signal is often dependent on several properties of the scattering surface such as the dielectric constant (water content) and geometric properties (shape and size). The former is expected to vary with vegetation type and season, while the latter varies with vegetation structure and canopy phenology. Undisturbed tropical moist forest ecosystems often comprise a relatively high density of tree types and an intact canopy. In comparison, CAFs have a less dense but well-stratified canopy that is often dominated by semideciduous trees. The C-Band SAR penetrates the vegetation canopy only to a limited extent. And as well as settlement and grassland land cover classes, forests have a high temporal

Corresponding author 
stability of SAR backscatter signals. According to Cartus et al., (2008), these land cover classes have the best contrast from agricultural land, when using the cross-polarised images (HV or $\mathrm{VH})$. Thus, considering the seasonal changes in canopy elements, temporal metrics from SAR images may be able to discriminate perennial agroforestry land cover. However, Schmullius et al., (2015) reported that texture measures are needed to discriminate settlement areas from forests.

\subsection{Research rationale}

For image classification objectives, texture measures from Grey Level Co-occurrence Matrix (GLCM) provide reliable information on the spatial relationship of images pixels (HallBayer, 2017). But, according to Hall-Beyer, (2017), the use of GLCM texture measures depends on the target feature and their characteristic spatial structure in the landscape. Since they have a direct influence on the reliability of SAR image classification results, the specular pattern and texture information extraction from SAR images are crucial metrics for image classification tasks.

In this study, we evaluated high-resolution reflectance from a mono-season multi-spectral optical image of RapidEye versus multi-seasonal SAR image textures information, for the discrimination and mapping perennial cocoa agroforestry land cover. Based on GLCM, we used four texture measures to capture the pixels spatial relationship in SAR image. Speckle information was retained and permitted a cross-correlation of images textures changes across several and different seasons. For discriminating land cover types, we used eight Random Forest (RF) models that differed mainly in composition and number of images as input bands. Using the resultant RF probability vectors, we evaluated uncertainties in the most reliable models to fit the data.

\subsection{Study site}

This study was conducted in the landscape of Bakoa (32N $734280 \mathrm{~m}$ E $510975 \mathrm{~m} \mathrm{~N}$ and $747435 \mathrm{~m} \mathrm{~N} \mathrm{501480m} \mathrm{E,} 123.28$ $\mathrm{km}^{2}$ ), which is located in the Bokito District of the Mbam and Inoubou Department, in the Centre Region of Cameroon (Figure 1). This area is classified as a savannah-forest transition zone. The topography features a rolling terrain and the altitude ranges between $500-900 \mathrm{~m}$ a.s.l. The vegetation is a mosaic of bushsavannah, subsistence farming, and perennial cocoa agroforests. These perennial agroforests are established mainly within or along patches of transition and gallery forests. The study area is situated in the humid forest bimodal agro-ecological zone, which is characterized by two dry and wet seasons. The total annual rainfall ranges between $1300-1500 \mathrm{~mm}$ with a long rainy season from August to November. The main dry season lasts about 5 months from November - April. The mean annual temperature is $25^{\circ} \mathrm{C}$.

\subsection{Data pre-processing}

We accessed available Sentinel-1A images (C-band Level-1 IW GRDH) for the study area from the Sentinel Scientific Data Hub, which is hosted by the European Space Agency (ESA). We selected temporal series of 50 images taken between March 2015 and April 2017, covering both the dry and wet seasons within this period. Using the image processing tools of Sentinel Application Platform (SNAP, 2017) version5.0, we produced image subsets for the study site and pre-processed sequentially (thermal noise removal, filtering with orbit file, radiometric calibration, geometric rectification, and terrain correction) from radar backscatter intensity values to sigma naught backscatter coefficients. We used both the co-polarised VV (Vertical transmit, Vertical received) and cross-polarised VH (Vertical transmit, Horizontal receive) bands of all images. We then projected the pre-processed images of $10 \mathrm{~m}$ resolution in WGS 1984 UTM Zone $32 \mathrm{~N}$. During the field campaigns conducted in 2015, 2016 and 2017, we collected ground information on land use and cover.

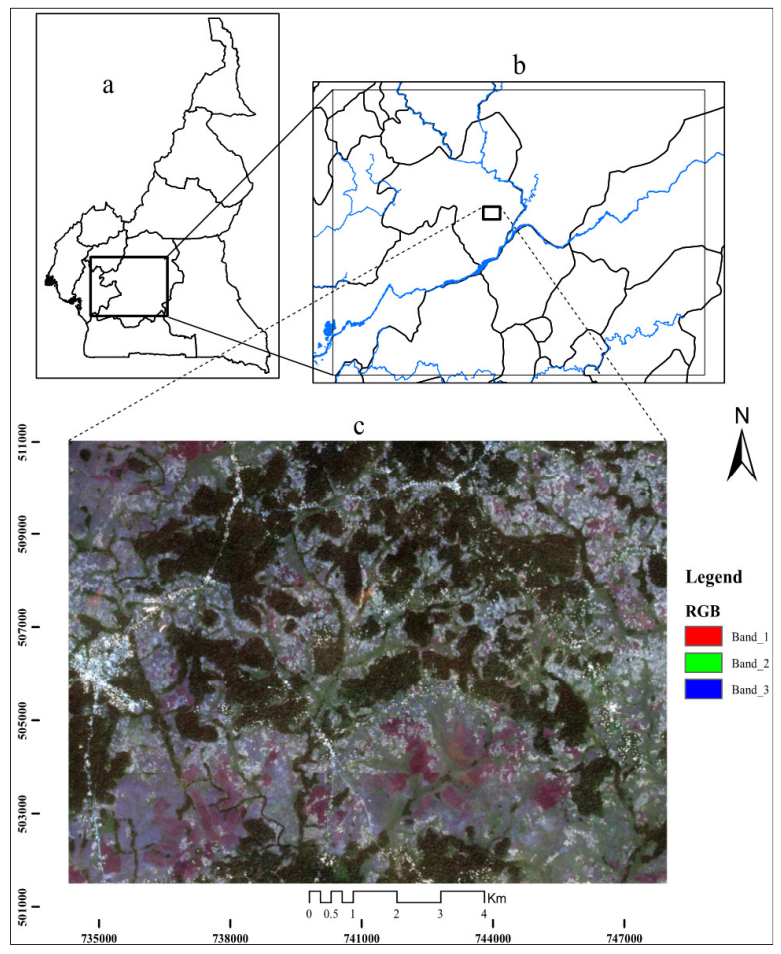

Figure 1. a) Study area located in Cameroon, b) Study landscape within the Bam and Inoubou administrative department, c) RapidEye false colour image (RGB: Blue, Green, and Red spectral bands) revealing mosaic of forest and savannah vegetation.

\section{MATERIAL AND METHODS}

\subsection{Image processing flow}

The image processing and analysis workflow consisted of: (1) Data acquisition and pre-processing as detailed in section 1.4 above. (2) Image processing: computation of GLCM texture images, extraction of textures for representative pixel (masks) of ground points (using SNAP tool). We used the Random Forest (RF) important variables criterion to remove noisy images, and initially selected a subsample of 10 (of the 50) important images in six wet and four dry seasons between 2015 and 2017 (Table 1). We co-registered the temporal series of images into separate stacks of VV, VH, and VV and VH image bands (Table 3). (3) Image classification by RF algorithm, using eight image stacks as classifier input (Table 3), and finally (4) Estimation of uncertainties in classified maps, in addition to accuracy metrics, as a basis for selecting the best classifier models. 


\subsection{Feature extraction: VIs and GLCM textures measures}

The monitoring of vegetation status and extent, from satellite remote sensing data, is often based on normalisation ratios of spectral bands, in the Visible and Near Infrared (NIR) spectrum (Silleos et al., 2006). These ratios are based mainly on the contrasting reaction of vegetation to the Red and NIR wavelengths, as an index for vegetation status and biomass abundance.

\begin{tabular}{|c|c|c|}
\hline $\begin{array}{l}\text { Acquisition } \\
\text { Date }\end{array}$ & Image Bands & $\begin{array}{l}\text { Pre-processed } \\
\text { data }\end{array}$ \\
\hline 05Jan2015 & $\begin{array}{l}\text { RapidEye Multi- } \\
\text { spectral optical } \\
\text { bands: Blue, Green, } \\
\text { Red, Red edge, NIR }\end{array}$ & $\begin{array}{l}\text { Top of } \\
\text { Atmosphere } \\
\text { (TOA) reflectance } \\
\text { and Vegetation } \\
\text { Indices (VIs) }\end{array}$ \\
\hline 06Jun2015 & \multirow{10}{*}{$\begin{array}{l}\text { Sentinel1A Synthetic } \\
\text { Aperture Radar } \\
\text { (SAR) Ground Range } \\
\text { Detected (GRDH) } \\
\text { Level 1 Data: co- } \\
\text { polarized (VV) and } \\
\text { cross-polarised (VH) } \\
\text { bands. }\end{array}$} & \multirow{10}{*}{$\begin{array}{l}\text { Backscatter } \\
\text { intensity in Sigma } \\
\text { naught }(\sigma 0) \text { and } \\
\text { Second order Grey } \\
\text { Level Co- } \\
\text { occurrence Matrix } \\
\text { (GLCM) Texture } \\
\text { measures }\end{array}$} \\
\hline 17Aug2015 & & \\
\hline 22Sep2015 & & \\
\hline 21Nov2015 & & \\
\hline 20Mar2016 & & \\
\hline 07May2016 & & \\
\hline 06Jul2016 & & \\
\hline 04Sep2016 & & \\
\hline 14Jan2017 & & \\
\hline 15Mar2017 & & \\
\hline
\end{tabular}

Table1: Remote sensing data acquisition; mono-date RapidEye $(5 \mathrm{~m})$ and multi-date Sentinel1 SAR $(10 \mathrm{~m})$ data.

The application of indices as NDVI for vegetation monitoring have faced several challenges (Mutanga and Skidmore, 2004), notably issue of saturation for biomass above certain thresholds, and which is common in moist tropical vegetation. And, although saturation may not be an issue over agricultural landscapes, reflectance from soil background often perturb discrimination of sparse vegetation or cropland from bare soil (Viña et al., 2011). Thus, vegetation monitoring from either specific or combination of VIs, depend on the target feature and the vegetation structure in the landscape. In this study, we used VIs whose values indicate the status and abundance of vegetation and biomass, and that minimise the effect of soil background on vegetation reflectance values (Wiesmair et al., 2016): NDVI, gNDVI, EVI2, SAVI, MSAVI. However, to provide additional information on vegetation characteristic and vitality, in transition between red absorption by chlorophyll and NIR reflection by plant cells, recent optical sensors have included additional spectral band - the red edge band of RapidEye and Sentinel2 (Delegido et al., 2011).

Since radar backscatter signals from a ground resolution cell is pseudorandom, the interaction of microwaves with terrain objects may not be predicted with certainty. Moreover, SAR images have speckle effect; because, the response signal of a resolution cell is a coherent interference from multiple scattering elements within the cell. Thus, texture information is as important as the multi-polarization information. Based on texture information extraction, the analysis of SAR images has been used for discrimination of cropland (Ghazaryan et al., 2018) and forest biomass estimation (Solberg et al., 2014). Often, the GLCM statistical approach is used in analysing SAR textures. The GLCM is a sparse matrix that stores co-occurrence probabilities of inter-pixel grey levels in an image (Haralick, 1979). These probabilities provide a second-order measure for texture features in an image: They represent conditional joint probabilities of all pairwise combination of grey levels $(G)$ in the spatial window of analysis, and depending on both the spatial orientation $(\theta)$ and displacement distance ( $\delta$ ). Computation of GLCM is faster for images with fewer grey levels, because the matrix is dimensioned to $\mathrm{G}$. The conditional probabilities are estimated as follows:

$$
\operatorname{Pr}(x)=\left\{C_{i j} \mid(\theta, \delta)\right\}
$$

Where, $\mathrm{C}_{\mathrm{ij}}=$ co-occurrence probability between grey level $\mathrm{i}$ and $\mathrm{j}$; and is defined by

$$
C_{i j}=P_{i j} / \sum_{i, j=1}^{G} P_{i j}
$$

Where, $P_{i j}=$ number of occurrence of grey levels $i$ and $j$ within the given window, for a certain $(\theta, \delta)$ pair; $\mathrm{G}=$ the quantized number of grey levels. The denominator sums up to the total number of grey level pairs $(i, j)$ within the analysis window.

Although different second-order statistics are commonly used to classify single images (Abdel-Hamid et al., 2018), some GLCM texture measures are auto-correlated (Haralick, 1979): A selection of a few texture measures may be reliable in achieving specific image analysis objective(s) (Hall-Beyer, 2017). We assess the accuracy of SAR images, covering several seasons, in discriminating perennial agroforestry land cover, using four less correlated GLCM texture measures: Contrast, Entropy, Correlation, and Variance. We estimated the textures measures from GLCM using a $5 \times 5$ moving window, an aggregate orientation of four directions, and one-pixel displacement (interpixel distance).

\subsection{Image feature classifier: Random Forest}

In this study, we used a non-parametric machine learning algorithm, the Random Forest (RF) ensemble as an image classifier. This algorithm, developed by Breiman, (2001), builds multiple decision trees for the same dataset based on random bootstrapping of sample training data. The random forest classifier is less influenced by the common issue of over-fitting and is able to handle a large number of variables. Firstly, each tree is built from a random subset (n) of two thirds of the original samples $(\mathrm{N})$ - the 'in-bag' data; and secondly, from a subset (m) randomly selected from the total (M) variables in the dataset $m t r y$, in each decision tree nodes are split using a best split variable - the one that yields the highest decrease in impurity (Hastie, 2009). The algorithm is a soft classifier on the basis of the probability voting of pixels belonging into the respective classes considered (Table 2). Compared to other non-parametric classification algorithms, it is less constrained by the need of extensive training and test data samples; this is due to an integrated out-of-bag (OOB) error estimation and accuracy test following a bootstrap sub-sampling on input data. Several sources provide additional details on the random forest algorithm (Hastie, 2009; Criminisi, 2011).

We ran eight RF models for the different images stacks as classifier input (Table 3). For each model, we evaluated the OOB error curve and mtry to prune decision trees to an optimal number. For a spatially explicit and unbiased representation of each land cover class in the RF models, we divided the extracted pixel information for each class into a stratified random sample of $70 \%$ and $30 \%$ pixels respectively for training and testing the models. Image classification was conducted using the random forest package (Liaw and Wiener, 2002) of R programming software 3.4.3 (R Core Team, 2017).

Several studies have used RF for classification of forest cover (Balzter et al., 2015) and cropland (Ghazaryan et al., 2018). Although Zhao et al., (2018)) reported data over-fitting and poor prediction with RF approach contrarily, when compared to other common methods, the RF algorithm provided relatively better 
classification of croplands (Ghazaryan et al., 2018) and mangrove vegetation (Abdel-Hamid et al., 2018). But, existing image processing steps may not be generalised or applicable for all cropping systems. For example, Loosvelt et al., (2012) observed high classification uncertainties for mixed pixels, which are typical for the heterogeneous boundaries between adjacent and internally homogeneous cropping fields. Mixed cropping systems are common in moist tropical landscapes. However, literature reporting on the processing and use of SAR images for mapping of tropical heterogeneous cropping systems, such as perennial agroforestry, is scarce.

\begin{tabular}{|c|c|c|}
\hline Class & Class Name & Description \\
\hline $\mathrm{Bu}$ & Built up & $\begin{array}{l}\text { Residents, commercial/markets, } \\
\text { industrial, administrative settings }\end{array}$ \\
\hline Es & $\begin{array}{l}\text { Earth } \\
\mathrm{road} / \mathrm{b} a r e \text { soil }\end{array}$ & $\begin{array}{l}\text { Land areas of exposed soil, bare } \\
\text { rocks, }\end{array}$ \\
\hline $\mathrm{Sv}$ & $\begin{array}{l}\text { Shrub/grasslan } \\
\text { d Savannah }\end{array}$ & $\begin{array}{l}\text { Imperata } s p \text { savannah land: } \\
\text { Shrubby and grassland areas which } \\
\text { have not been converted to farm }\end{array}$ \\
\hline W & Water & $\begin{array}{l}\text { River, ponds, seasonal and } \\
\text { permanent swamps }\end{array}$ \\
\hline Af & $\begin{array}{l}\text { Perennial } \\
\text { agroforests }\end{array}$ & $\begin{array}{l}\text { Land areas used for cocoa } \\
\text { production with various degrees of } \\
\text { canopy stratification: canopy/shade } \\
\text { trees are mainly deciduous }\end{array}$ \\
\hline $\mathrm{Fa}$ & $\begin{array}{l}\text { Subsistence } \\
\text { farming }\end{array}$ & $\begin{array}{l}\text { Savannah and forest land areas that } \\
\text { have been converted essentially for } \\
\text { permanent or seasonal subsistence } \\
\text { crop production; including farm } \\
\text { fallows }\end{array}$ \\
\hline Fs & $\begin{array}{l}\text { Transistion } \\
\text { forest }\end{array}$ & $\begin{array}{l}\text { Disturbed and gallery forest } \\
\text { patches, secret/cultural forest, } \\
\text { hunting forest: have a more } \\
\text { permanent and less stratified } \\
\text { canopy structure }\end{array}$ \\
\hline
\end{tabular}

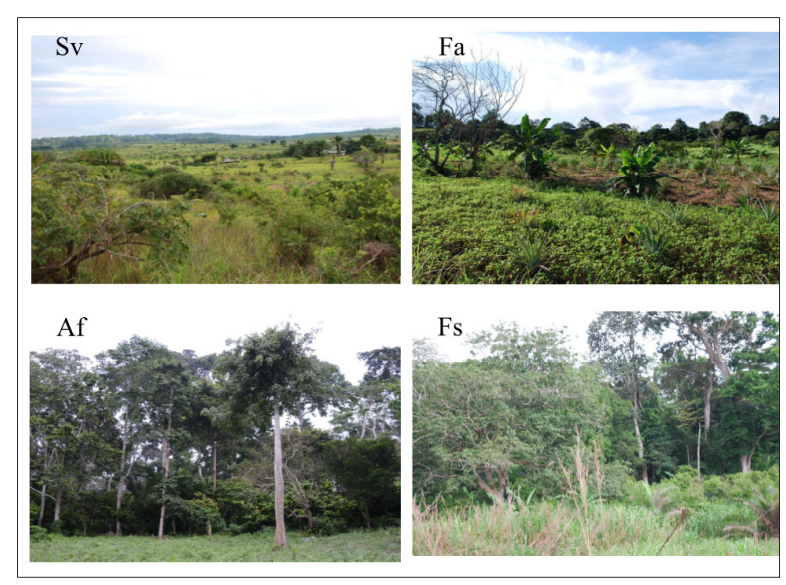

Figure 2. The range of vegetation land covers differ mainly in the density of woody biomass, which changes with season or phenological period (class acronyms are described in Table 2).

\subsection{Estimating classification uncertainty of models}

In remote sensing mapping, the validity and reliability of classified maps are often decided on basis of estimated overall accuracy and kappa coefficient (Ghazaryan et al., 2018). Values such as user's and producer's accuracy are prone to errors and uncertainties (Unwin, 1995). As a soft classifier, however, the RF algorithm provides the possibility for assessing data- and computation-related uncertainties (Loosvelt et al., 2012). In our analysis, we used user's accuracy (omission error), producer's accuracy (commission error), overall accuracy and Kappa statistics - which compares results of a chance classification versus our RF model accuracy. However, the pixel-based classification methods are prone to uncertainties coming from either the use of unreliable data or complex processing procedures (Unwin, 1995). Thus, RF algorithm, as a soft classification, provides a vector $\left(P_{u}\right)$ of classification probability or votes for each image pixel $-P_{u}=P_{1}, P_{2}, P_{3}, \ldots \ldots, P_{n}$ for a classification with n categories, and $P_{i}$ denotes the probability of belonging to class $i$ (Table 2).

\begin{tabular}{|c|c|c|}
\hline $\begin{array}{l}\text { Data } \\
\text { Categories }\end{array}$ & $\begin{array}{l}\text { Model } \\
\text { Group }\end{array}$ & Image bands \\
\hline \multirow{2}{*}{$\begin{array}{l}\text { RE: } \\
\text { Dry season } \\
\text { Multi- } \\
\text { spectral } \\
\text { RapidEye } \\
\text { Image }\end{array}$} & RE1 & $\begin{array}{l}\text { TOA Reflectance of B, G, R, } \\
\text { Red Edge, and NIR: } 5 \text { Bands }\end{array}$ \\
\hline & RE2 & $\begin{array}{l}\text { TOA Reflectance and } \\
\text { Vegetation Indices (VIs): } 10 \\
\text { Bands }\end{array}$ \\
\hline \multirow{3}{*}{$\begin{array}{l}\text { GL: } \\
\text { Multi-date } \\
\text { and season } \\
\text { SAR } \\
\text { GLCM } \\
\text { Textures }\end{array}$} & GL1 & $\begin{array}{l}\text { Multi-date VV GLCM Textures: } \\
40 \text { Bands }\end{array}$ \\
\hline & GL2 & $\begin{array}{l}\text { Multi-date VH GLCM Textures: } \\
40 \text { Bands }\end{array}$ \\
\hline & GL3 & $\begin{array}{l}\text { Multi-date VV and VH GLCM } \\
\text { Textures: } 80 \text { Bands }\end{array}$ \\
\hline \multirow{3}{*}{$\begin{array}{l}\text { GLI: } \\
\text { Multi-date } \\
\text { and season } \\
\text { SAR } \\
\text { intensity } \\
\text { and GLCM } \\
\text { Textures }\end{array}$} & GLI1 & $\begin{array}{l}\text { Multi-date SAR VV Simga0 } \\
\text { intensity and VV GLCM } \\
\text { Textures: } 50 \text { bands }\end{array}$ \\
\hline & GLI2 & $\begin{array}{l}\text { Multi-date SAR VH Sigma0 } \\
\text { intensity and VH GLCM } \\
\text { Textures: } 50 \text { bands }\end{array}$ \\
\hline & GLI3 & $\begin{array}{l}\text { Multi-date SAR VV plus VH } \\
\text { Sigma0 intensity and, VV plus } \\
\text { VH GLCM Textures: } 100 \text { bands }\end{array}$ \\
\hline
\end{tabular}

Table 3: The respective image stacks, used to compare the Random Forest (RF) classification accuracy.

In this study, in addition to model OOB error estimation, we evaluated classification uncertainties of RF models using the maximum classifier probability (U), and a weighted uncertainty measure entropy: the Shannon entropy (H) (Shannon, 1948; Vajapeyam, 2014). These uncertainties were calculated as:

$$
\begin{aligned}
& U=1-P_{\text {max }} \\
& H=-\sum_{i=1}^{N} P_{i} \cdot \log P_{i}
\end{aligned}
$$

Where, $\quad P_{i}=$ probability of belonging to class $i$ and

$P_{\max }=$ maximum probability vote for a pixel's class.

$\mathrm{N}=$ the total number of classes considered for analysis.

By considering the entire range of values in a pixel's probability vector, $\mathrm{H}$, compared to $\mathrm{U}$ that only makes use of Pmax, provides a more robust measure of uncertainty; it has a maximum value at highest entropy - equal probability votes for all classes (Table 2). Loosvelt et al., (2012) showed that $\mathrm{H}$ is reliable for evaluating uncertainties in mapping cropland from SAR images. However, our study area is characterised by heterogeneous cropping 
systems and is located in a tropical landscape (Figure 2). Thus, we may expect a different trend of uncertainty estimates from classified maps. For the best RF models, based on kappa accuracy, we computed and analysed $\mathrm{U}$ and $\mathrm{H}$ uncertainties for the classified maps, and the land cover classes considered in the study area (Table 2). The uncertainty estimations and analysis were conducted in Spyder IDE (Integrated Development Environment) of Anaconda distribution for Python programming software (Anaconda Development Team, 2017)

\section{RESULTS}

All models evaluation had classification accuracies above $70 \%$. Classification error and the sensitivity in discriminating land cover classes was different for each model. The evaluation of classification uncertainties is presented for the models with the highest classification reliability, which, in increasing order of importance, were RE1, GLI3, and GL3.

\subsection{Land cover classification accuracy (contribution of VH versus VV)}

Table 4 summarizes the classification results for all the eight RF models. All models had a reliable overall accuracy (OA) above $70 \%$. However, compared to using VV or VH bands separately, the use of both co- and cross-polarization bands (GL3) resulted in the highest classification accuracy. The GL3 model had a highest overall accuracy of $88.07 \%$ and kappa of 85.37; and, compared to other models, the OOB error estimate was least with $12.85 \%$. Also, classification from the multi-spectral optical image (RE1 model) had a reliable overall accuracy of $81.08 \%$, but it had a lower kappa $76.92 \%$. Compared to the GL3 model, the OOB error difference of $+7 \%$ was observed for the RE1.

\begin{tabular}{|c|c|c|c|}
\hline $\begin{array}{l}\text { Model } \\
\text { Group }\end{array}$ & $\begin{array}{l}\text { Overall Accuracy- } \\
\text { OA \% (95\% CI) }\end{array}$ & $\begin{array}{l}\text { Kappa } \\
(\%)\end{array}$ & $\begin{array}{l}\text { OOB } \\
\text { Error \% }\end{array}$ \\
\hline RE1 & $81.04(79.68,82.35)$ & 76.92 & 19.18 \\
\hline RE2 & $80.15(78.76,81.48)$ & 75.75 & 19.46 \\
\hline GL1 & $82.74(80.02,85.23)$ & 78.73 & 17.12 \\
\hline GL2 & $81.65(78.74,84.32)$ & 77.35 & 18.47 \\
\hline GL3 & $88.07(85.52,90.31)$ & 85.37 & 12.85 \\
\hline GLI1 & $78.80(75.85,81.53)$ & 73.87 & 19.66 \\
\hline GLI2 & $82.97(80.21,85.48)$ & 78.96 & 18.71 \\
\hline GLI3 & $85.07(82.42,87.47)$ & 81.70 & 13.69 \\
\hline
\end{tabular}

Table 4: Classification accuracies of different feature models based on the Random Forest (RF) classifier algorithm.

Separately, both VV and VH GLCM derived texture measures were poor in the prediction of non-vegetated land covers, and more so when both bands were included in the same model. When included as input layers, the SAR backscatter intensity did not improve classification accuracy. Likewise, the inclusion of vegetation indices from the multi-spectral optical image, taken during a dry season, did not improve classification accuracy.

The thematic land cover map from RE1 and GL3 models are shown in Figure 3. Visually, RE1 map shows a relatively intact and continuous expanse of transition forest patches (Figure 3a). Contrarily, the classified map from GL3 revealed that transition forest cover is highly fragmented by cocoa agroforests into smaller patches (Figure 3b). Also, from classification reliability estimates in Figure 4, the RE1 model was more reliable in delineating non-vegetation land features. SAR-based texture images had a high reliability in delineating vegetation landscape features (Sv, Af, Fa, and Sf). Thus, although multi-spectral optical image had a better classification prediction of land cover classes in general, it was less reliable in discriminating perennial agroforest and transition forest land cover.

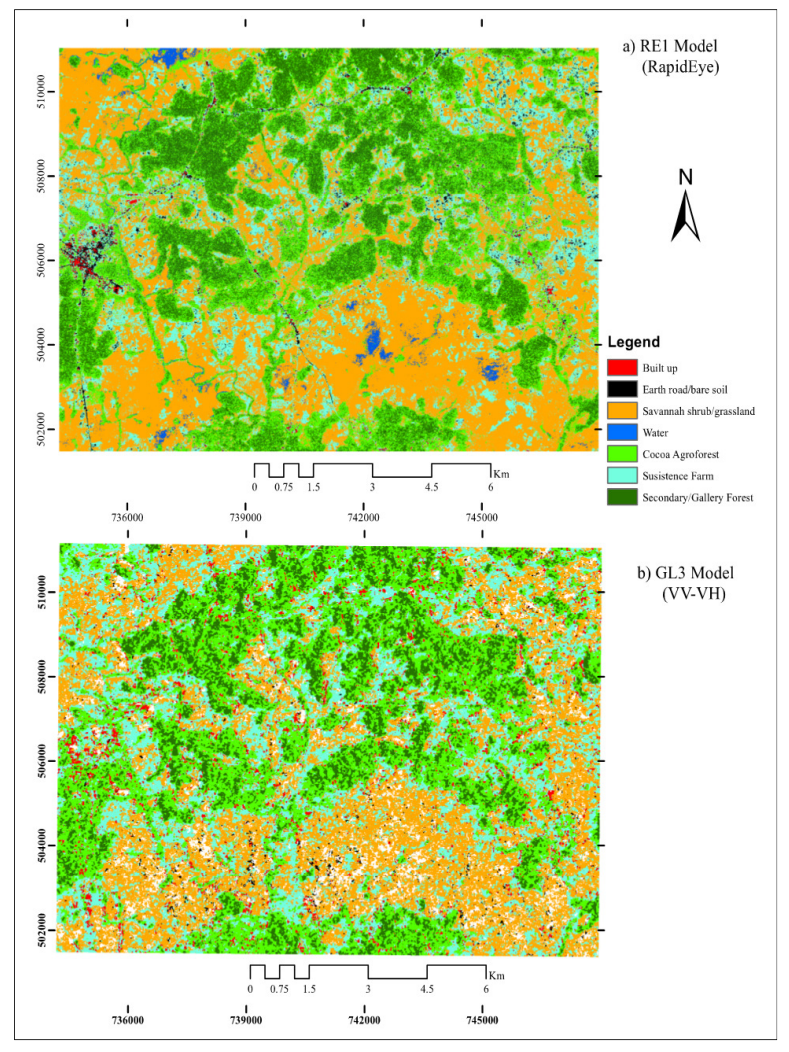

Figure 3. Thematic land cover maps from a) dry season multispectral optical image, and b) multi-seasonal SAR derived texture images (legend and north arrow apply to both images).

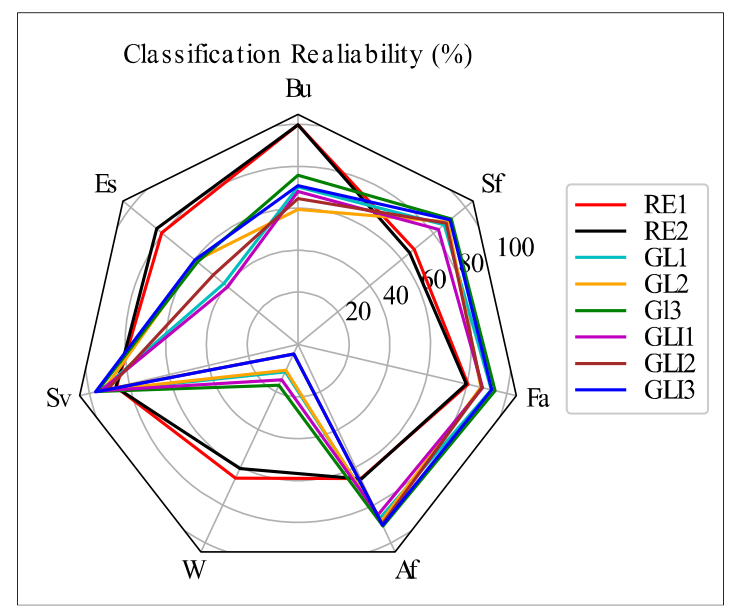

Figure 4. The multi-season SAR derived GLCM textures images had a high reliability (100 - commission error) to delineate vegetated land cover. Non-vegetated land cover were better classified by multi-spectral optical image (RE1, RE2). 


\subsection{Uncertainty in discriminating vegetation land cover}

The classification results from dry season RapidEye multispectral optical image (RE1) had a low overall uncertainty for entire image and land cover types. From the cumulative estimates of class probabilities in Figure 5, classification uncertainty from the RE1 converges at probability of around 0.6 for both $\mathrm{U}$ and $\mathrm{H}$, whereas the uncertainty from GL3 map converges at higher probabilities -0.7 and 0.9 respectively for $\mathrm{U}$ and $\mathrm{H}$. About $90 \%$ of pixels classified by RE1 had $\mathrm{H}$ uncertainties below 0.4; compared to about $50 \%$ of pixels for GL3 (Figure 5). This difference is less obvious in the cumulative plot of U. Thus, uncertainty difference between RE1 and Gl3 was better revealed by Shannon entropy or $\mathrm{H}$ uncertainty.

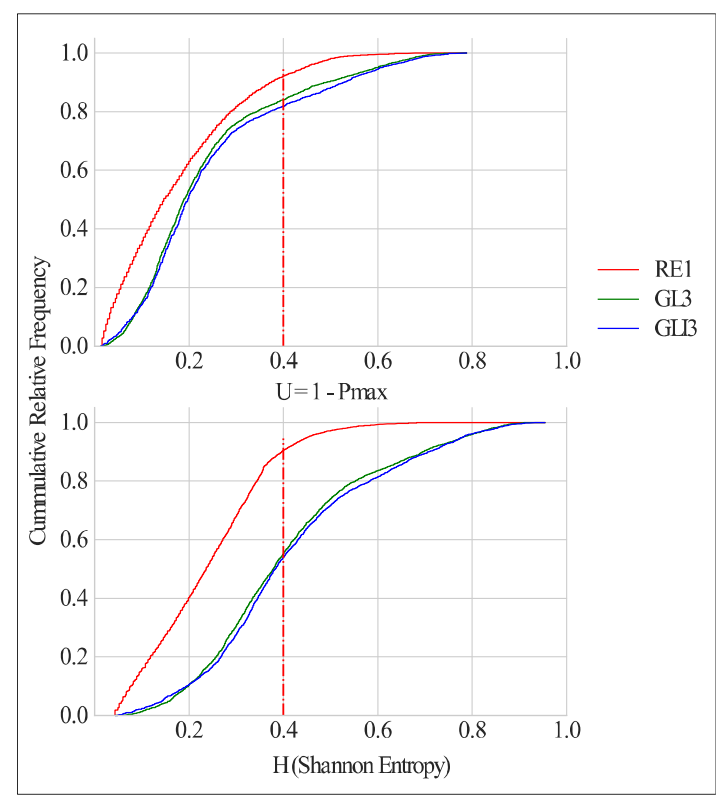

Figure 5. The Shannon entropy $(\mathrm{H})$ clearly reveals uncertainty difference in thematic maps from RE1 and GL3 RR models: As example, the proportion of pixels with uncertainty below 0.4 .

The individual class uncertainties are compared in Figure 6. Although the classified map from the multi-spectral image (RE1 model) had a lower uncertainty for the entire image, individual class uncertainty was, compared to other land cover types, high for perennial cocoa agroforests and transition forest cover (Figure 6a). Contrarily, the multi-seasonal SAR image textures, from the GL3 model, had high classification uncertainty for the entire image; But, perennial agroforests and transition forests were discriminated with relatively lower individual class uncertainty (Figure 6b): The median individual class uncertainties were in a range between 0.2 and 0.4 , which is comparable to those obtained from single multi-spectral image (RE1).

\section{DISCUSSION AND CONCLUSION}

\subsection{Discussion}

This research aimed at assessing the reliability of GLCM derived textures images, from multi-season Sentinel1A SAR images, to discriminate perennial cocoa agroforestry and subsistence farm practices from forest cover. We included other land cover classes in classification analysis to derive a thematic land cover map of the study landscape; and assessed the contribution of perennial agroforestry in fragmenting the remaining patches of transition forest. Compared to a "business as usual" classification from a mono-season, multi-spectral optical image (RE1), the texturebased map (GL3) had a reliable overall accuracy, which is consistent with other mapping accuracies from C-band SAR ( Ghazaryan et al., 2018). Following the high overall accuracy and a corresponding low individual class uncertainty in this study landscape of heterogeneous vegetation cover, the multi-date texture information from SAR images provides a reliable classifier input for discriminating of perennial agroforestry land cover from transition forest.

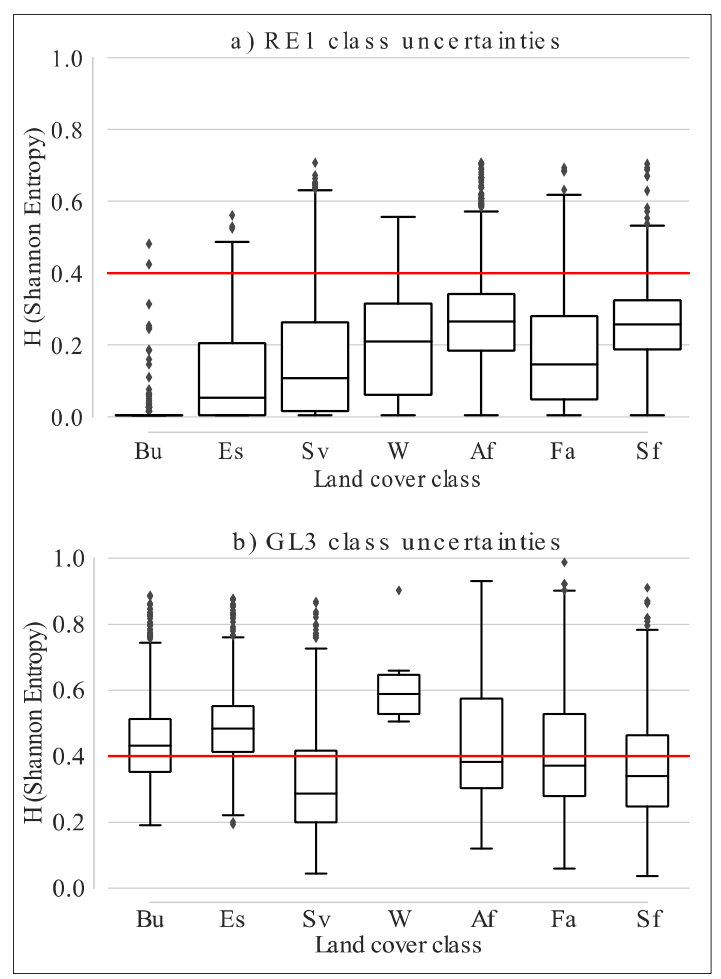

Figure 6: Comparison of individual class Shannon entropy $(\mathrm{H})$ or uncertainty, for, a) single date multi-spectral optical image (RF model RE1) b) multi-season SAR image texture-based classification (RF model GL3)

As observable from multi-seasonal SAR image derived land cover map (Figure $3 b$ ), the transition forest patches are vastly fragmented by perennial agroforests. These fragmentations are consistent with field observations. The transition forest patches are mostly owned by families and community groups for hunting, performing traditional rituals, and potential expansion of cocoa agroforests parcels. The canopy of cocoa agroforests and transition forests have a similar optical reflectance, rendering a distinction from a mono-season, multi-spectral image, acquired in dry season, difficult. The similarity of canopy parameter for both classes, in the case of a dry season, is observable in their class uncertainty distribution (Figure 6a). A metric of seasonal changes in phenology, based on radar backscatter, discriminated the two land cover with low class uncertainties (Figure 6b), that were comparable to uncertainties obtain from the single-season multi-spectral image. 
In the SAR image map of GL3, the important variables for classification were the VH Variance and Correlation of SAR images acquired in a dry season and, followed by VV Contrast of images in a wet season. The behaviour of $\mathrm{VH}$ and $\mathrm{VV}$ backscatter signal is different over vegetated areas. Over vegetation cover, there is much volume scattering of the radar signals. And volume scattering tends to cause a depolarisation of the return signals, which then corresponds to a high backscatter in crosspolarization ( $\mathrm{VH}$ or $\mathrm{HV}$ ) bands. Thus, the $\mathrm{VH}$ bands have a high sensitivity to vegetation canopy. The inter-class variations in canopy parameter are represented in SAR images as visual or coherent edges (i.e. abrupt changes in DNs between neighbouring image pixels). And such visual edges, and as well non-edgy intraclass variations between pixels, are effectively measured by the GLCM Variance. While the GLCM Correlation, termed as 'interior texture' (Hall-Beyer, 2017), takes high values that characterize areas away from coherent edges with many subtle and irregular variations. And such variations are more prominent in the dry season. These explain the high importance of GLCM Variance and Correlation image textures for dry season VH image. The importance of $\mathrm{VH}$ image is in line with observations of Cartus et al., (2008), that the mean annual variations of crosspolarised (HV) band best differentiated agricultural land from other land cover types. In the wet season, the intra-class differences in canopy parameters, and likewise inter-class volume scattering, are less obvious between the vegetation types. The major differences in vegetation canopies, their vertical structure, are captured in co-polarized (VV) bands. The GLCM Contrast is sensitive to areas with visual edges, which may explain the high importance of VV Contrast Texture in the wet season images. In the rainy season, therefore, volume scattering may be less crucial to delineate different vegetation cover.

Considering the heterogeneous land cover in the landscapes, we reliably estimated land cover classification uncertainty from multi-date and -season SAR image texture measures. However, our findings contradict that of Loosvelt et al., (2012): $\mathrm{U}$ and $\mathrm{H}$ uncertainties were not comparable in this study landscape. Compared to $\mathrm{U}$, the entropy or $\mathrm{H}$ revealed better the difference in the cumulative proportion of pixels between RE1 and GLE maps at, for example, uncertainty 0.4 (Figure 5). A linear slope of RE1 reflects low classification uncertainty from the multispectral image map. The cumulative relative frequency of Shannon entropy $(\mathrm{H})$ followed a sigmoid curve (Figure 5), and represents a complete range of probabilities for each image pixel: It reflects well the soft boundary between land cover classes, which explains the sigmoid curve of cumulative relative frequency. Compared to perennial agroforests, the low individual class uncertainty for transition forest (Figure 6b) is logical, considering a high temporal stability of radar backscatter over forest area (Schmullius et al., 2015). The high variability in tree density and structure between cocoa agroforests, may result in high intra-class variations in SAR backscatter intensity. This explains their high $\mathrm{H}$ uncertainty. Likewise, the diversity in farm subsistence crop types and stages may explain the low $\mathrm{H}$ for the class. The savannah lands have a consistent canopy structure in each season, except for areas converted to subsistence farming or previous farms that have been left fallow. Their regular canopy structure, during each season, may explain the low, class uncertainty.

Classification validation based on accuracy metrics as overall, user, and producer accuracies are influenced by sample class distribution in training data (Heydari and Mountrakis, 2018).
Thus, the differences in pixel resolution between images types ( $5 \mathrm{~m}$ for RapidEye and $10 \mathrm{~m}$ for SAR C-Band) resulted in different reference class sizes, which may explain the high overall accuracy for SAR image. A relatively reduced number of reference pixels may result in low estimates of misclassification probability (commission or omission errors). The sample size is not as influential in classification validation by uncertainty measures. The GLCM texture measures were tailored to discriminate vegetation types, and less sensitive to nonvegetation cover. We estimated the GLCM textures using a $5 \times 5$ window, considering the $10 \mathrm{~m}$ pixel resolution for sentinel1 SAR. However, different window sizes may influence both texture values and the classification accuracy. The analysis of different window sizes was not the aim of this study and may be a subject for further investigated for this and other landscapes.

\subsection{Conclusion}

In this study, we show the reliability of open source Sentinel1 SAR data in discriminating and mapping perennial agroforestry and farms within forest cover, in tropical conditions where optical satellite data are less available.

a) The use of multi-date C-Band SAR is reliable in discriminating perennial agroforestry land cover from transition forests.

b) The decisive GLCM texture measure for delineating perennial agroforest vary with season, and for the polarization band used. Selected image texture metrics from both VV and VH polarization image are essential to monitor the changes in canopy structure of perennial agroforests across seasons.

c) Classification validation using uncertainty estimates by Shannon entropy $(\mathrm{H})$ is effective in the validation of individual class accuracy, and for making a general inference from classified maps.

This work has provided new insights in the use of SAR images and selection of scenes for reliable mapping of perennial agroforestry land cover. The procedure is an opportunity in landscape monitoring, such as estimating the contribution of agroforestry to national and regional REDD+ strategies. However, there is a need to assess classification uncertainties in different agroforestry dominant landscapes - for an operational regional application in the Congo Basin sub-region.

\section{ACKNOWLEDGEMENTS}

This study was conducted under the Special Research Fund of Ghent University, and through which RapidEye image was procured. Fieldwork was supported by the World Agroforestry Centre's Country programme in Cameroon. We thank the European Space Agency for providing the freely accessible archive of Sentinel1 SAR image under the Corpenicus Open Data Hub. We express gratitude to developers and contributors to both $\mathrm{R}$ and Python programming and data mining software, which are open source and free.

\section{REFERENCES}

Abdel-Hamid, A., Dubovyk, O., Abou El-Magd, I., Menz, G., 2018. Mapping Mangroves Extents on the Red Sea Coastline in Egypt using Polarimetric SAR and High Resolution Optical Remote Sensing Data. Sustainability 10, 646.

https://doi.org/10.3390/su10030646

Anaconda, Inc (nee Continum Analytics) 2017: Anaconda 
Python distribution, Open source Software for data science and machine learning, version 4.4., https://www.anaconda.com

Balzter, H., Cole, B., Thiel, C., Schmullius, C., 2015. Mapping CORINE land cover from Sentinel-1A SAR and SRTM digital elevation model data using random forests. Remote Sens. 7, 14876-14898. https://doi.org/10.3390/rs71114876

Breiman, L.E.O., 2001. Random Forests 5-32.

Copernicus Sentinel data 2017, processed by European Space Agency(ESA).http://www.esa.int/Our_Activities/Observing_the _Earth/Copernicus

Criminisi, A., Shotton, J., Konukoglu, E., 2011. Decision Forests for Classification, Regression, Density Estimation, Manifold Learning and Semi-Supervised Learning.

Delegido, J., Verrelst, J., Alonso, L., Moreno, J., 2011. Evaluation of sentinel-2 red-edge bands for empirical estimation of green LAI and chlorophyll content. Sensors 11, 7063-7081. https://doi.org/10.3390/s110707063

Ghazaryan, G., Dubovyk, O., Löw, F., Lavreniuk, M., Kolotii, A., Schellberg, J., Kussul, N., 2018. A rule-based approach for crop identification using multi-temporal and multi-sensor phenological metrics. Eur. J. Remote Sens. 51, 511-524. https://doi.org/10.1080/22797254.2018.1455540

Hall-Beyer, M., 2017. Practical guidelines for choosing GLCM textures to use in landscape classification tasks over a range of moderate spatial scales. Int. J. Remote Sens. 38, 1312-1338. https://doi.org/10.1080/01431161.2016.1278314

Haralick, R.M., 1979. Statistical and structural approach to texture. Proceeding IEEE vol 67 no 5 67, 786-804. https://doi.org/10.1109/PROC.1979.11328

Hastie, T., Tibsharani, R., Friedman, J., 2009. Springer Series in Statistics The Elements of. Math. Intell. 27, 83-85. https://doi.org/10.1007/b94608

Heydari, S.S., Mountrakis, G., 2018. Effect of classifier selection, reference sample size, reference class distribution and scene heterogeneity in per-pixel classification accuracy using 26 Landsat sites. Remote Sens. Environ. 204, 648-658. https://doi.org/10.1016/j.rse.2017.09.035

Liaw, A., Wiener, M., 2002. Classification and Regression by randomForest 2, 18-22.

Loosvelt, L., Peters, J., Skriver, H., Lievens, H., Van Coillie, F.M.B., De Baets, B., Verhoest, N.E.C., 2012. Random Forests as a tool for estimating uncertainty at pixel-level in SAR image classification. Int. J. Appl. Earth Obs. Geoinf. 19, 173-184. https://doi.org/10.1016/j.jag.2012.05.011

Mutanga, O., Skidmore, A.K., 2004. Narrow band vegetation indices overcome the saturation problem in biomass estimation Int. J. Remote Sens. 25, 3999-4014. https://doi.org/10.1080/01431160310001654923

Norgrove, L., Hauser, S., 2013. Carbon stocks in shaded Theobroma cacao farms and adjacent secondary forests of similar age in Cameroon. Trop. Ecol. 54, 15-22.
R Core Team (2017). R: A language and environment for statistical computing. R Foundation for Statistical Computing, Vienna, Austria. URL https://www.R-project.org/.

RapidEye, 2018. Application of te RapidEye Red Edge Band. RapidEye Red Edge White Pap. 1-8.

Schmullius, C., Thiel, C., Pathe, C., Santoro, M., 2015. Remote Sensing Time Series. https://doi.org/10.1007/978-3-319-159676

Shannon E. Claude, 1948. A Mathematical Theory of Communication. Bell Teleph. Syst. Tech. Publ. 27, 379-423.

Silleos, N.G., Alexandridis, T.K., Gitas, I.Z., Perakis, K., 2006. Vegetation indices: Advances made in biomass estimation and vegetation monitoring in the last 30 years. Geocarto Int. 21, 2128. https://doi.org/10.1080/10106040608542399

Solberg, S., Næsset, E., Gobakken, T., Bollandsås, O.M., 2014. Forest biomass change estimated from height change in interferometric SAR height models. Carbon Balance Manag. 9, 1-12. https://doi.org/10.1186/s13021-014-0005-2

Sonwa, D.J., Weise, S.F., Nkongmeneck, B.A., Tchatat, M., Janssens, M.J.J., 2016. Structure and composition of cocoa agroforests in the humid forest zone of Southern Cameroon. Agrofor. Syst. 1-20. https://doi.org/10.1007/s10457-016-9942-y

SNAP 2017- European Space Agency (ESA) Sentinel Application Platform version 5.0.0, http://step.esa.int

Unwin, D.J., 1995. Geographical information systems and the problem of "error and uncertainty." Prog. Hum. Geogr. 19, 549-558. https://doi.org/10.1177/030913259501900408

Vajapeyam, S., 2014. Understanding Shannon 's Entropy metric for Information 1-6.

Viña, A., Gitelson, A.A., Nguy-Robertson, A.L., Peng, Y., 2011. Comparison of different vegetation indices for the remote assessment of green leaf area index of crops. Remote Sens. Environ. 115, 3468-3478. https://doi.org/10.1016/j.rse.2011.08.010

Wiesmair, M., Feilhauer, H., Magiera, A., Otte, A., Waldhardt, R., 2016. Estimating Vegetation Cover from High-Resolution Satellite Data to Assess Grassland Degradation in the Georgian Caucasus. Mt. Res. Dev. 36, 56-65. https://doi.org/10.1659/MRD-JOURNAL-D-15-00064.1

Zhao, K., Suarez, J.C., Garcia, M., Hu, T., Wang, C., Londo, A., 2018. Remote Sensing of Environment Utility of multitemporal lidar for forest and carbon monitoring : Tree growth, biomass dynamics , and carbon fl ux. Remote Sens. Environ. 204, 883-897. https://doi.org/10.1016/j.rse.2017.09.007 